\title{
Alemtuzumab: The Right Choice in the Management of Relapsing- remitting Multiple Sclerosis?
}

\section{Murat Yildiz* and Barbara Tettenborn}

Department of Neurology, Kantonsspital Sankt Gallen, Switzerland

Multiple sclerosis (MS) is a chronic inflammatory disease of the central nervous system with multifocal demyelinated lesions, axonal loss and gray matter atrophy [1]. The etiology of MS is unknown, but it is thought to involve autoimmune processes. Alemtuzumab is a monoclonal antibody directed against CD52 and mainly targets T and $\mathrm{B}$ cells, and to a lesser degree natural killer cells and monocytes [2]. The first reported use of alemtuzumab in clinical trials for MS were between 1991 and 2002 and involved only 58 patients [3]. It was demonstrated that it successfully reduced disease activity in relapsing-remitting (RR) and moderately in secondary progressive (SP) MS patients [3]. In the pivotal phase III clinical trials $12 \mathrm{mg}$ /day and $24 \mathrm{mg}$ /day alemtuzumab was compared in RRMS patients against subcutaneous interferon beta 1a (IFN $\beta$-1a) $44 \mu \mathrm{g}$ three times weekly. In the 2 year study $51 \%$ patients in the interferon beta 1a group relapsed compared with $35 \%$ patients in the alemtuzumab group [4]. Noteworthy, in this study $1 \%$ had immune thrombocytopenia (ITP) and $16 \%$ of the patients treated with alemtuzumab had thyroid disorders, though most were mild or moderate in severity [4]. ITP usually occurred several months after administration of alemtuzumab [4]. Moreover, alemtuzumab reduced the risk of sustained increasing disability as measured by Expanded Disability Status Scale (EDSS) compared with IFN $\beta-1 a$ [5]. An additional, study provided follow-up clinical data over a period of five years documenting persistent efficacy and superiority over interferon $\beta-1 \mathrm{a}[6]$.

Alemtuzumab's efficacy in MS may implicate a more extensive immune modulation that possibly forms a rebalanced immune system, leading to a reduction in MS disease activity [7]. Succinctly, alemtuzumab showed significantly better suppression of relapses, and MRI lesion development, with less brain volume loss in the phase II and III studies. Based on these results alemtuzumab was recently licensed for the treatment of relapsing-remitting multiple sclerosis in the European Union. But the clinical data for alemtuzumab could not convince the FDA that its benefits outweigh its side effects and thus alemtuzumab failed approval in the United States. In clinical practice it will be administered in 2 cycles. The first treatment cycle consists of 5 consecutive days of daily intravenous alemtuzumab infusions. One year later the second cycle is administered on 3 days. Lymphocytes are depleted and it can take several years to return to pre-treatment levels [8]. The main raised concerns in the clinical studies are so far about autoimmune disease and infection. In a study with 248 MS patients treated with alemtuzumab the cumulative risk for auto immune diseases was $22.2 \%$, most cases occurred between 12 and 18 months following first dose and for up to 5 years [9]. Adequate risk management should be considered for up to 5 years after the last treatment cycle and should include monthly platelet counts, urinalysis for blood, as well as quarterly thyroid monitoring $[8,10]$. Additionally, serum IL-21 may serve as a biomarker for the risk of developing autoimmunity after alemtuzumab treatment [10]. The long-term risk for adverse effects will be determined after introduction of alemtuzumab in clinical practice. The Canadian Agency for Drugs and Technologies in Health assessed alemtuzumab to be cost-effective treatment [11]. Definite recommendations are difficult to outline in the light of alemtuzumab's safety profile. But available clinical data support alemtuzumab as second-line therapy in highly active RRMS [12] and for RRMS patients with treatment failures due to undesirable side effects, or breakthrough disease activity.

\section{References}

1. Compston A, Coles A (2002) Multiple sclerosis. Lancet 359: 1221-1231.

2. Klotz L, Meuth SG, Wiendl H (2012) Immune mechanisms of new therapeutic strategies in multiple sclerosis-A focus on alemtuzumab. Clin Immunol 142 25-30.

3. Coles AJ, Cox A, Le Page E, Jones J, Trip SA, et al. (2006) The window of therapeutic opportunity in multiple sclerosis: evidence from monoclonal antibody therapy. J Neurol 253: 98-108.

4. Coles AJ, Twyman CL, Arnold DL, Cohen JA, Confavreux C et al. (2012) Alemtuzumab for patients with relapsing multiple sclerosis after diseasemodifying therapy: a randomised controlled phase 3 trial. Lancet 380: 18291839

5. Cohen JA, Coles AJ, Arnold DL, Confavreux C, Fox EJ, et al. (2012) Alemtuzumab versus interferon beta 1 a as first-line treatment for patients with relapsing-remitting multiple sclerosis: a randomised controlled phase 3 trial. Lancet 380: 1819-1828.

6. Coles AJ, Fox E, Vladic A, Gazda SK, Brinar V, et al. (2012) Alemtuzumab more effective than interferon $\hat{I}^{2}-1 a$ at 5 -year follow-up of CAMMS223 clinical trial. Neurology 78: 1069-1078.

7. Freedman MS, Kaplan JM2, Markovic-Plese S3 (2013) Insights into the Mechanisms of the Therapeutic Efficacy of Alemtuzumab in Multiple Sclerosis. $\mathrm{J}$ Clin Cell Immunol 4.

8. Coyle PK (2014) Current evaluation of alemtuzumab in multiple sclerosis Expert Opin Biol Ther 14: 127-135.

9. Cossburn M, Pace AA, Jones J, Ali R, Ingram G, et al. (2011) Autoimmune disease after alemtuzumab treatment for multiple sclerosis in a multicenter cohort. Neurology 77: 573-579.

10. Jones JL, Phuah CL, Cox AL, Thompson SA, Ban M, et al. (2009) IL-21 drives secondary autoimmunity in patients with multiple sclerosis, following therapeutic lymphocyte depletion with alemtuzumab (Campath-1H). J Clin Invest 119: 2052-2061.

11. Management of Relapsing-Remitting Multiple Sclerosis (2013). Ottawa (ON) Canadian Agency for Drugs and Technologies in Health.

12. Edan G, Le Page E (2013) Induction therapy for patients with multiple sclerosis: why? When? How? CNS Drugs 27: 403-409.

*Corresponding author: Murat Yildiz, Department of Neurology, Cantonal Hospital of Saint Gallen, Rorschacher Strasse 95, Switzerland, Tel: +49 1726142 404; E-mail: yildizmur@yahoo.com

Received January 21, 2014; Accepted February 19, 2014; Published February 25,2014

Citation: Yildiz M, Tettenborn B (2014) Alemtuzumab: The Right Choice in the Management of Relapsing-remitting Multiple Sclerosis? J Neurol Neurophysiol 5 196. doi:10.4172/2155-9562.1000196

Copyright: (c) 2014 Yildiz M, et al. This is an open-access article distributed under the terms of the Creative Commons Attribution License, which permits unrestricted use, distribution, and reproduction in any medium, provided the original author and source are credited. 